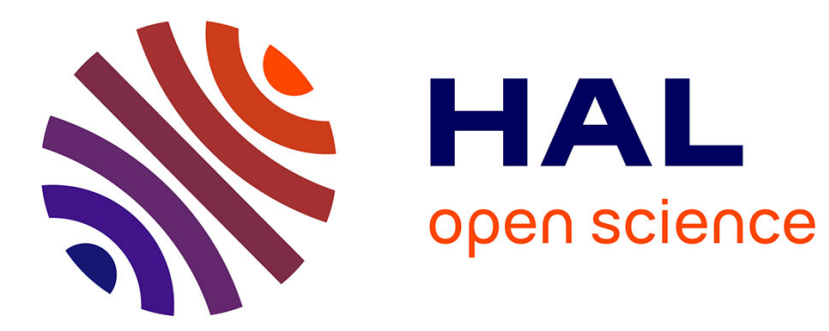

\title{
A New Method for Modeling Learners in a Collaborative Human Learning Environment
}

\author{
Noureddine / Seddari, Sara Kerraoui, Marwa Drissi
}

\section{To cite this version:}

Noureddine / Seddari, Sara Kerraoui, Marwa Drissi. A New Method for Modeling Learners in a Collaborative Human Learning Environment. 2020. hal-03013956

\section{HAL Id: hal-03013956 \\ https://hal.science/hal-03013956}

Preprint submitted on 19 Nov 2020

HAL is a multi-disciplinary open access archive for the deposit and dissemination of scientific research documents, whether they are published or not. The documents may come from teaching and research institutions in France or abroad, or from public or private research centers.
L'archive ouverte pluridisciplinaire HAL, est destinée au dépôt et à la diffusion de documents scientifiques de niveau recherche, publiés ou non, émanant des établissements d'enseignement et de recherche français ou étrangers, des laboratoires publics ou privés. 


\title{
A New Method for Modeling Learners in a Collaborative Human Learning Environment
}

\author{
Noureddine Seddari ${ }^{1,2}$, Sara Kerraoui ${ }^{1}$, and Marwa Drissi ${ }^{1}$ \\ ${ }^{I}$ Department of Computer Science, 20 August 1955 University of Skikda, Algeria. \\ ${ }^{2}$ LIRE Laboratory, Software Technologies and Information Systems Department, \\ University of Abdelhamid Mehri, Constantine, Algeria. \\ n. seddari@univ-skikda.dz \\ kerraouisara@hotmail.fr \\ marwadrissi2016@gmail.com
}

\begin{abstract}
Computer Environments for Human Learning (CEHL) offers several pedagogical activities to the learners such as: learning, self-assessment, communication with other learners and the problem solving, etc. this latters can benefit from these services at any time and from any place. But, the learner's isolation and the lack of a support service have a negative impact on his learning, his achievements, and especially on his motivation during his educational activities. So, to cop this, tutoring is required in CEHL. It can be defined as a social relationship between an expert person called tutor and a person in difficulty, the learner. Since, tutoring is often the ideal solution for learners; this is why several research works were introduced in recent years. However, Most of them have found several difficulties concerning the tutor's work. This paper presents a novel arch to model learners in a collaborative human learning environment. The aim is to propose a method for the Modeling of learner-tutor. Moreover, we based on the learner's response to a questionnaire in order to create his or her own profile. This space offers all the tools and mechanisms to support and promote collaboration between learnertutors in this way the problems of learners is solved.
\end{abstract}

Keywords: CEHL, Tutoring, Human learning, Auto-evaluation, Collaboration, Clustering, Learner, Tutor, Learner-tutor.

\section{$1 \quad$ Introduction}

A Computer Environments for Human Learning (CEHL) is an environment designed to promote human learning, otherwise defined, the association of human (learner, teacher, tutor) and artificial (computer agents, who can play different roles) actors and to offer them conditions for interaction, locally or through computer networks, or conditions for access to local or distributed training resources (human and/or mediatized) [1].

C. Cherkaoui [2] presents an approach to the term "environment" in a place covering one or more systems, which may be real or virtual. The term "computing" refers to the use of information and communication technologies (ICTs) by integrating computers into teaching to enable the learning process to be enhanced. For the term "learning", it is a method based on the transmission and construction of knowledge. The term "human", this aspect first appeared during the evolution of the field of computerized environments for learning, under the influence of linguists to take into account interactions and to make them more "human" in a learning process. 
Finally, this author identifies different actors, different functions and different roles. The main actors and functions are: the learner, the trainer, the designer, the manager and the informant.

Tutoring is an activity that has been applied in several areas such as: Learning, Education, Health, etc [3]. In the field of education, this activity can be a solution to all the problems caused during the learning process. Indeed, it allows supporting learners during all their activities in the system. In recent years, tutoring has become an indispensable task in CEHL. It can be defined as a social relationship between an expert person called tutor and a person in difficulty, the learner. Its study concerns both the follow-up of the students and the instrumentation of the tutor's activities. The activity of tutoring consists in helping its learners through the tutor(s). Tutors have several functions and roles. These roles differ according to the skills and abilities of the tutors themselves.

Several systems adopting tutoring have been developed. In these systems, the tutor can have many roles and functions. But, his absence for technical or family reasons can influence his actions towards his learners. In addition, the tutor's lack of mastery of some roles makes the requests for assistance sent by the students unanswered. This forces learners to look for other tutors with the desired role. This type of situation occurs when learners ask for assistance on the content of learning objects (or teaching modules), then the tutors are not specialists or do not master the concepts of these learning objects.

In these situations, the obvious strategy, then, is to propose to offer learners another dimension in their tutoring model by assigning the task of tutoring to the learners so becoming learner-tutor. This space offers all the tools and mechanisms to support and promote collaboration between the learner tutors in order to solve the learners' problems then to propose a new method of clustering learners in CEHL and this is based on the work of Y. Lafifi [4]. The aim of this method is to combine the tw o algorithms (complement algorithm and complementarity algorithm) that aims at grouping learners. But here, several questions arise: What are the methods used for clustering? How do you cluster the learner-tutors? How to handle the clustering process? The proposed approach supplies answers to this questions, that is, to design a tutoring system which has several services and options for learners who can also be tutors (learner-tutor in our system).

This paper is organized as follows: The second presents the computer environments for human learning (CEHL). The third section describes related works, both to point out the many contributions of previous researchers from which our approach was inspired. The approach that we propose are shown in the fourth section. Finally, section 5 concludes the work and underlines our perspectives.

\section{Computer Environments for Human Learning (CEHL)}

N. Balacheff [5] defines a CEHL as: «An environment that integrates human (student or teacher) and artificial (computer agents) and provides them with conditions for interaction, locally or through computer networks».

Thus, CEHL offers a set of networked computer tools that enable the management and dissemination of training: access, sharing or transfer of knowledge, access to sources by downloading or consulting on the net..., and communication between its actors [6].

\subsection{Tutoring}

Tutoring is a supervisory activity based on a human tutor monitoring students during a learning activity [7]. The concept of tutoring was proposed by Bruner (1983), and is based on the idea that a learner who has done very well in a course can help another learner in a learning or problem-solving situation. The role of the tutor is not to give a direct answer to the problem posed, but to guide, accompany and help the "tutor" who encounters difficulties in certain modules and who wishes to improve. 
The main objective of tutoring is to help learners to improve their learning level and apply operational pedagogical methods and tools [8].

\subsection{The tutor and his activity in support}

The tutor is a person with a relationship with distance learning who is available every day to answer all the questions of the learners and respond to their problems in a very short time [9].

According to Auvergne and Carrey [10], the tutor is referred to as a central mediating and binding function in online education, between a learner and a group of learners, between learners and the training content, and between learners and the training institution. Figure 1 presents the "Binder" tutor.

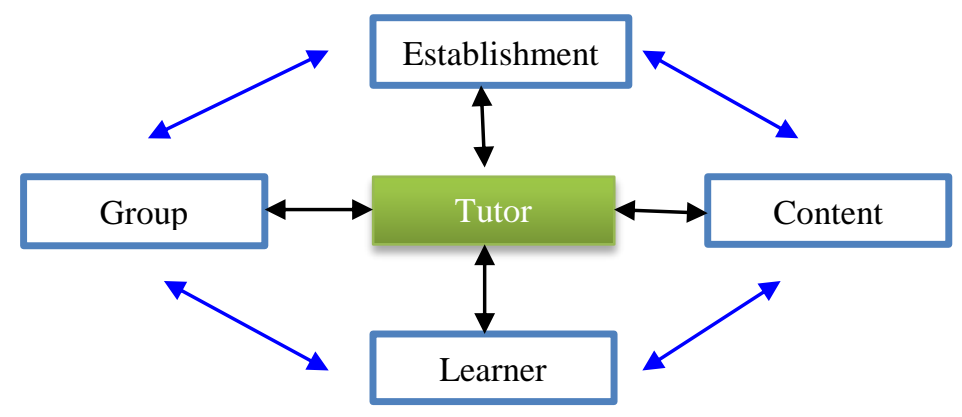

Fig. 1. The "Binder" tutor [10]

\subsubsection{The skills of the online tutor}

Studies were proposed in the 1980s $[11,12]$ to answer the following questions: Would it be better for students to have an expert tutor to solve their problems, or do they just need a good tutor? A good tutor in this case means being able to empower students, helping them to learn from their mistakes and build their learning.

Indeed, the tutor is not necessarily an expert in the field. They may only have sufficient knowledge to meet the students' expectations in certain number of pedagogical subjects, but they do not perforce have all the knowledge that the student must master at the end of his or her training, as their role is not to provide answers to the problems posed, but to guide the student [13].

\subsubsection{Roles of the tutor}

Several studies in the field of distance learning (DL) have discussed the roles and functions of the online tutor. In fact, different names have been used to refer to it in online interaction, such as: coach [14], facilitator [15], motivator, mentor, mediator [16], moderator [17], tutor [18], etc.

Also, depending on the tutor's learning strategy (individual or collaborative) and types of support (pedagogical, organizational, etc.), the tutor may have several roles [19] [20].

\subsection{Computer-assisted collaboration}

Collaborative computer-assisted tutoring is a strategy for supporting learners by a group of tutors. Indeed, it is a form of collaboration between tutors for the follow-up of learners. In other words, it is to study the way in which technology-assisted collaborative tutoring can facilitate and develop distance tutoring. Also, It is to determine how tutor collaboration and technology facilitate the monitoring of learners and guiding them [21]. Figure 2 presents an illustrative diagram of collaborative tutoring. 


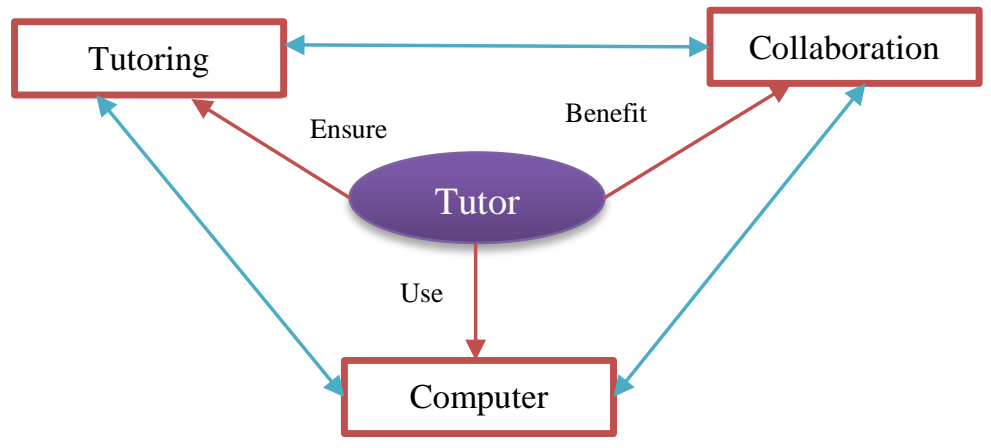

Fig. 2. Illustrative diagram of collaborative tutoring.

\subsection{E- Learning}

E-learning (or Electronic-learning) is online learning focused on the development of skills by the learner and structured through interaction with the tutor and peers [22]. It offers a wide range of tools to enable teachers and learners to be innovative, creative and resourceful in all learning activities. Teachers and learners can easily customize the digital learning resources to suit the pace and level, appropriate to any learning style and degrees of intelligence. In addition, it provides virtual learning worlds where learners can learn through simulations, games, remote control of realworld tools and devices, or collaboration [23].

\subsubsection{E-learning actor}

According to S. Riot [24]. The E-Learning actors involved in the use phase of an elearning device are:

> The administrator: The administrator is responsible for maintaining the technical environment, that is ensures the installation and maintenance of the system, manages access rights, creates links to other systems and external resources (administrative files, catalogues, educational resources, etc.). It is in charge of the mediatization of the contents and the formatting of the educational resources and their integration into the learning environment.

The learner : The learner is a person engaged and active in a process of acquiring or developing knowledge and implementing it. They can consult online or download educational content, participate in online learning activities (individual or collaborative activities), exchange data, carry out exercises; self-evaluation and send work to their tutor for correction. Communication between learner and tutor can be individual or group. It is possible to create discussion topics and collaborate on joint work by using means of working and communicating with several people: videoconferencing, e-mail, forums, chats, annotations, shared whiteboards, etc.

> The tutor: A tutor is a person responsible for passing his knowledge to a student or trainee through an activity called tutoring. In the CHEL, the tutor has several roles. 


\section{Background and related works}

There are several techniques that have been used to model user in general and learner in particular in order to structure their knowledge. The approaches presented in this section can be combined to create the user model [20].

- The perturbation model: the perturbation model is an extension of overlay model. Like the latter, the learner's knowledge is represented by a subset of the expert's knowledge, and the extension is summarized in the possibility of representing the learner's false knowledge. These are considered as perturbations of the expert knowledge, thus becoming an interest of this modeling technique. Unfortunately, this approach is time-consuming [25].

-Overlay model: Overlay model is a widely adopted technique to model a learner's knowledge. In this type of model, the learner's knowledge is represented by a subset of the expert's knowledge. It is generally expressed by a model established by an expert in the domain by associating a value to each concept of the domain model. The main advantage of this modeling technique is that it is simple to implement [26].

- Fuzzy logic for learner modeling: It is known that there are difficulties and problems with education systems where there is no direct interaction between teacher and students. These problems are due to the collection of information about learner knowledge levels and behaviours, thus increasing the diagnosis of learner uncertainty.

One possible approach to deal with this uncertainty is the fuzzy logic [27]. Fuzzy logic is capable of dealing with uncertainty in problems caused by incomplete data. Thus, this technique allows calculating data with words that cannot be calculated with other methods.

- Bayesian net: this technique is used to manage uncertainty in user modeling . A Bayesian net is an acyclic oriented graph in which the nodes represent the variables and the arcs represent the probabilistic dependence between variables. In the learner model, nodes can represent the different components or dimensions of a learner such as knowledge, emotions, learning styles, motivation, goals, etc. [28,29]

- Machine Learning : Learner modeling involves a process of making inferences about learner behaviour by taking into account the learner's level of knowledge, cognitive abilities, preferences, skills, abilities, etc.. The process of observing the learner's action and behaviour in a tutoring system should be done by the automated system. This observation induces a model designed to predict future actions by the automatic learning techniques [30].

- Learner modeling based on ontologies: Ontology is defined as a specification of a conceptualization of a field of knowledge. More concretely, ontology supports the structured representation of concepts, and the properties of each concept describing characteristics and attributes of the concept. In addition, the ontology can be designed to share and reuse knowledge easily [31].

\section{$4 \quad$ Proposed Approach}

Collaboration between the different actors is one of the most important activities in Computer Environments for Human Learning (CEHL), The approach discussed in this paper consists of grouping the learners who play the role of tutor (learner-tutor) in order to facilitate an essential task in the CEHL, which is tutoring. The main objective of our system is to offer tutor learner- tutor a collaborative space to facilitate collaborative work between them. 


\subsection{Functional architecture of the proposed system}

The architecture below defines the functionalities of our system. Thus, the functional relations between the different actors. Figure 2 shows the functional architecture of the proposed system.

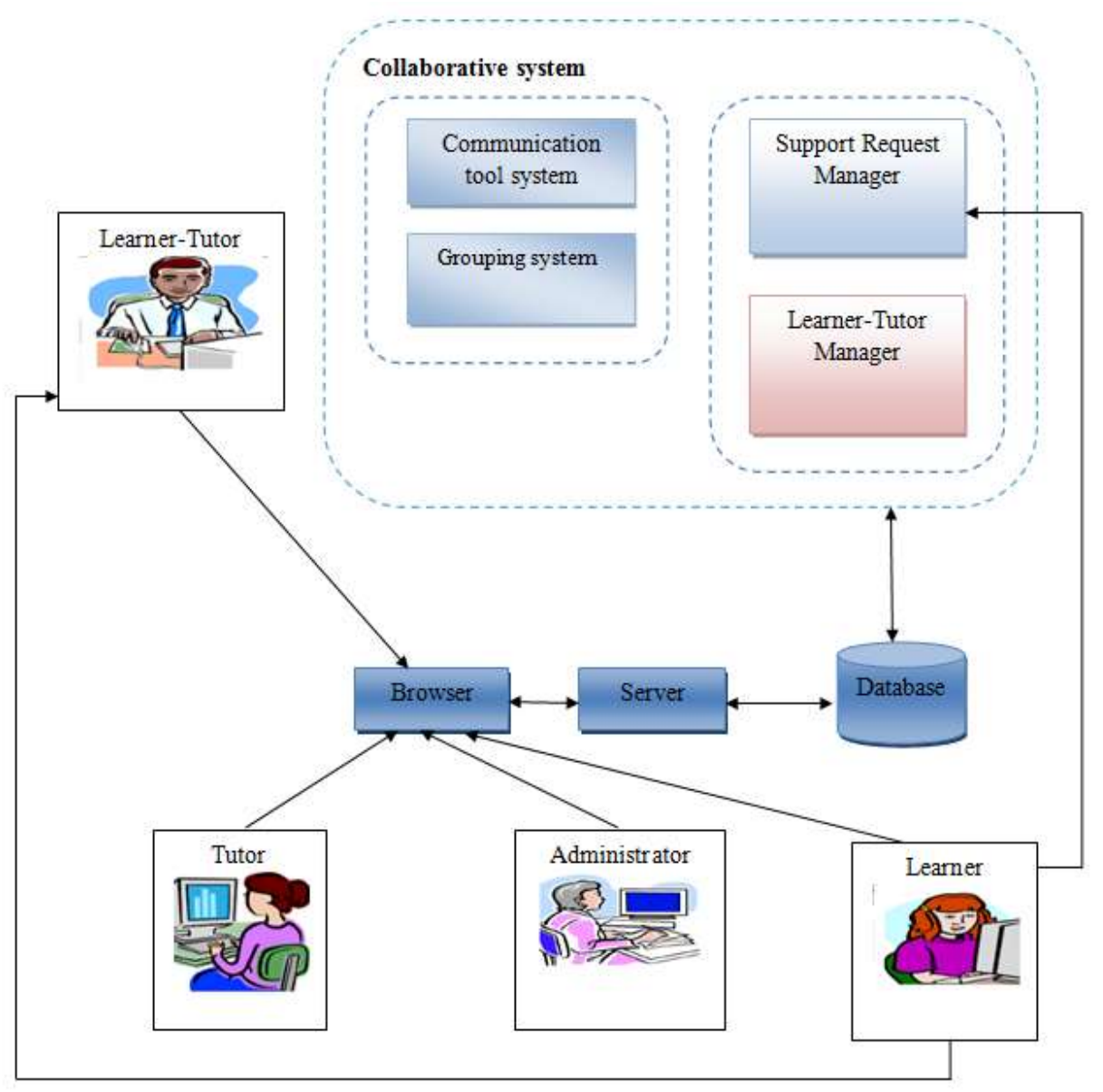

Fig. 3. Functional architecture of the proposed system.

-Tutoring system: It is the system that contains two modules: The Manager of Requests for Assistance and the Manager of Actors (Learners, Learners-Tutors and Tutors).

- Support Request Manager: It contains all accepted and refused requests for assistance, and for each learner-tutor group the administrator assigns a maximum six (6) learners for each group.

- Actors Manager: This module manages all the actors registered in our system as well as other tasks such as learner to learner tutors.

- Collaborative system: This system contains two modules: the communication tools manager and the grouping system.

- Communication Tools: The actors of our system can choose a communication tool such as messaging and private or public forum to contact each other. In addition, they can access or chat if there is a meeting.

- Learner-Tutor Grouping System: It contains two grouping algorithms: Complement Algorithm and Incremental Complementarity Algorithm [4]. These algorithms are used to group the tutors, but their absence for technical or family reasons may influence their actions towards their learners. In addition, the tutor's lack of mastery of some roles makes requests for assistance sent by learners unanswered. This forces them to look for other tutors with the desired role, to overcome this 
constraint we proposed that the learner plays the role of the tutor.

We chose these two algorithms because of their simplicity in grouping learner-tutors, in fact our idea that is the learner plays the role of a tutor made them more efficient because each group of learner-tutors contains all the necessary roles that the learner needs.

\section{Conclusion}

Our work focuses on the combining techniques for clustering of tutors according to their role during the tutoring task.

In this work we proposed to assign some learners to play the role of tutor. After the tutor learner creates his profiles and the administrator grouped them according to special algorithms (Complement Algorithm, Complementarity Algorithm).

The proposed system allows to manage conflicts between learners in the tutoring task and to provide the learner with a workspace to facilitate communication with the tutoring learners.

As future work, we will consider implementing our method and apply it also in MOOCs (Massive Open Online Courses) that require a large number of learners to facilitate their assessments using clustering.

\section{References}

1. Tchounikine, P. (2002). Quelques éléments sur la conception et l'ingénierie des EIAH. Actes des deuxiémes assises nationales du GDR I3, Information Interaction Intelligene, Nanc.france.

2. Cherkaoui, C., Megder, E., \& Mammass, B. S. D. (2005). Quelques Pistes Pour Améliorer Le Développement Des Environnements Informatiques Pour L'apprentissage Humain. In 3rd International Conference SETIT.

3. Bar-Eli, N., Bar-Eli, M., Tenenbaum, G., \& Forlin, C. (1998). The tutoring process and its manifestation in the classroom behaviour of tutors and tutees. British educational research journal, 24(3), 283-300.

4. Lafifi, Y., Bendjebar, S.,et Zedadra, A. (2014). A K-complementarity Technique for Forming Groups of Tutors in Intelligent Learning Environments. CIT, Journal of Computing and Information Technology, 22(2), 115-130.

5. Balacheff, N., Baron, M., Desmoulins, C., Grandbastien, M., \& Vivet, M. (1997). Conception d'Environnements Interactifs d'Apprentissage avec Ordinateur. Tendances et perspectives. Actes des journées nationales du PRC IA, 315-338.

6. Tchounikine, P. (2002). Pour une ingénierie des Environnements Informatiques pour l'Apprentissage Humain.

7. Alonso, M. (2009). Conception de l'interaction dans un EIAH pour la modélisation orientée objet. Doctor thesis in Computer Science, Université du Maine, France. http://cyberdoc. univ-lemans. fr/theses/2009/2009LEMA1007. Pdf

8. Deschenes, A.-J., et Paquette D. (1996 ). Programme de formation continue des enseignants (Première année), sous la direction de A.-J. Deschenes, Québec, Centre Romand d'Enseignement a Distance et Tele-université.

9. Daele, A., \& Docq, F. (2002 ). Le tuteur en ligne, quelles conditions d'efficacité dans un dispositif d'apprentissage collaboratif à distance? 19ème colloque de l'AIPU (Association Internationale de Pédagogie Universitaire). Louvain-laNeuve, Belgique. 29- 31 Mai.

10. Teutsch, P., Bourdet, J. F., \& Gueye, O. (2004). Perception de la situation d'apprentissage par le tuteur en ligne. Actes de la conférence Technologies de l'Information et de la Communication pour l'Education, UTC Compiegne, 1-8.

11. Auvergne, J. F., \& Carrey, J. C. (2004). Tutorat et autonomie de l'apprenant en FOAD par Internet. Conférence TICE Méditerranée, Nice,2004. Disponiblesur:http://atrium.unice.fr/nte/colloque/communication_ fichiers/10 carreyauvergne.pdf. (Consulte le 18/10/2015).

12. Barrows, H. S. (1988). The tutorial process. Southern Illinois Univ. 70 pages.

13. Baudrit, A. (2000). Le tutorat dans les universités anglo-saxonnes: des idées pour les universités européennes? » Editions L'Harmattan, 194 pages.

14. Collison, G., Elbaum, B., Haavind, S., \& Tinker, R. (2000). Facilitating Online Learning: Effective Strategies for Moderators. Madison, WI, USA: Atwood Publishing. 216 pages.

15. Murphy, K. L., Drabier, R., \& Epps, M. L. (1998). A constructivist look at interaction and 
collaboration via computer conferencing. International Journal of Educational Telecommunications, 4 (2), 237-261.

16. English, S., \& Yazdani, M. (1999). Compute Supported Cooperative Learning in a Virtual University. Journal of Computer Assisted Learning, 15 (1), 2-13.

17. Salmon, G. (2003). E-moderating: The key to teaching and learning online. Psychology Press. 256 pages.

18. Gerrard, C. (2002). Promoting best practice for e-tutoring through staff development. In Proceedings of Networked Learning 2002: 3rd International Conference, Lancaster University and University of Sheffield, 26-28 March. Disponible sur http://www.networkedlearningconference.org.uk/ past/nlc2002/ proceedings /papers/15.htm (Consulte le 23/05/2015).

19. George, S. Prévot, P. Arnghar, Y. et Pierson, J., (2004). Complixité ses situation pédagogique elearning dans un contexte mufti_culturel,colaboratif et synchrone. conférence TICE Méditerrannée, Nice,France.

20. Bendjebar, S. (2016). Utilisation des Techniques de Data Mining pour la Modélisation des Tuteurs (Doctoral dissertation).

21. Lewis, R. (1995). Editorial: Professional learning. Journal of Computer Assisted Learning, Vol 11, $N^{\circ}$ 4. pp 193-195.

2. Holmes B., Gardner J.R. (2006). E-Learning: Concepts and Practice. London: Sage Publications Ltd.

23. Olojo, O-J., Adewumi M-G., Ajisola K-T. (2012). ELearning and Its Effects on Teaching and Learning in a Global Age. International Journal of Academic Research in Business and Social Sciences, Vol. 2, No. 1.

24. Bontcheva, K., \& Wilks, Y. (2005). Tailoring automatically generated hypertext. User Modeling and User-Adapted Interaction, 15 (1-2), 135-168.

25. RIOT, S., Guin, N., \& Jean-Daubias, S. (2004). Assistance à l'enseignant dans le cadre de l'EIAH AMBRE: conception d'un générateur de problèmes. Rapport de recherche LIRIS (stage de DEA Informatique et PFE INSA), LIRIS-CNRS.

26. de Koch, N. P. (2001). Software Engineering for Adaptive Hypermedia Systems-Reference Model, Modeling Techniques and Development Process.

27. Nguyen, L., et Do, P. (2008). Learner model in adaptive learning. In Proceedings of World academy of science, engineering and technology, 45, 396-401.

28. Conati, C., Gertner, A., et Vanlehn, K. (2002). Using Bayesian networks to manage uncertainty in student modeling. User Modeling and User-Adapted Interaction, 12(4), 371417.

29. Jameson, A. (1995). Numerical uncertainty management in user and student modeling: An overview of systems and issues. User Modeling and User-Adapted Interaction, 5 (3-4),193251.

30. Drigas, A., Argyri, K., et Vrettaros, J. Decade review (1999-2009). Artificial intelligence techniques in student modeling. In Proceedings of the 2nd World summit on the knowledge society (WSKS 2009), Chania, Crete, Greece, 16-18 Septembre. 552-564.

31. Chrysafiadi, K. et Virvou, M. (2012). Evaluating the integration of fuzzy logic into the student model of a web-based learning environment. Expert Systems with Applications, 39(18), 13127-13134. 